\title{
Interactive comment on "Hydrodynamic characterization of past flash-flood events and their associated hazards from dendrogeomorphological evidence in Caldera de Taburiente National Park (Canary Islands, Spain)" by Julio Garrote et al.
}

Anonymous Referee \#2

Received and published: 18 August 2016

Summary of the paper: In this paper an approach for the assessment of past flashfloods in ungauged basins based on dendrogeomorphological information is presented. The used dendrogeomorphological parameters are wounds in trees (scars) resulting from currents in combination with sediments. The authors set up both a rainfall-runoff-model and a 2D-hydrodynamic numerical model. In a case study for the 1997 flood, they make two simulations: (1) A model run with the rainfall-runoff-model 
$50 \mathrm{~m}^{3} / \mathrm{s}$. (2) They used the 2D-model to analyse which peak flow matches best to the found tree wounds dedicated to the 1997 flood. This results in a peak flow of about $1200 \mathrm{~m}^{3} / \mathrm{s}$. The authors also make an extensive discussion on uncertainties in their analyses.

General/major comments: Generally, the paper addresses an important field of hydrology, namely the assessment of floods in ungauged basins. The data availability in such regions is poor and additional information help to understand the characteristics of the basin and the river system. An interesting method to gain additional information is using dendrogeomorphological data sources. However, there are some weak points in the paper, which should be improve before publication: (1) Since the main focus of the paper is on the use of dendrogeomorphological data sources, there is a lack of explanations in the methods section, how the dendrogeomorphological data sources are obtained in detail. Later in this paper the uncertainties in the data become very important. Hence, the methods section should include more information on how wounds in trees (scars) are generated (only by currents or in combination with sediments); how the time-dependent development of wounds can be described; how wounds are defined as significant; do the data only result from visual inspections; what is the data quality etc.. (2) A vital result of the paper is the large discrepancy in the model runs resulting in $50 \mathrm{~m}^{3} / \mathrm{s}$ and $1200 \mathrm{~m}^{3} / \mathrm{s}$. There is a very extensive discussion on uncertainties in data and methods, which is honorable. From my point of view the discrepancy of the results is that large so talking about "uncertainties" is critical. Isn't it more a signal, that either data or methods are simply not suitable to answer the research question? Where is the border between uncertainty and infeasibility? Especially since both precipitation and dendrogeomorphological data include major uncertainties the conclusion that the obtained results could improve flood hazard and risk analysis is questionable.

Minor comments: P5, L6: Include more information on dendrogeomorphological data and methods (see above). P6, L10: The POT extreme value statistics is based on data lasting $<24$ hours and $>24$ hours. Please explain this more in detail. From my point

Printer-friendly version

Discussion paper 
of view one has to choose defined duration levels (e.g. 6 hours, 12 hours etc.) and perform the statics for each series individually. P7, L24: Please explain more in detail NHESSD how the v1997 topography was built. P10, L11: The explanations given in sec. 4.3 can only hardly justify this large discrepancy found in the model results. Figure 8: Please add the original data (plotting positions) in the plot; the differences in the results seems a little bit strange. Please check also the whole calculation.

Interactive

comment

Final recommendation: Considering the comments above I recommend publication of the manuscript in NHESS after major revision.

Interactive comment on Nat. Hazards Earth Syst. Sci. Discuss., doi:10.5194/nhess-2016-206, 2016. 